\title{
Liquid Scintillation Counting
}

National Cancer Institute

\section{Source}

National Cancer Institute. Liquid Scintillation Counting. NCI Thesaurus. Code C122170.

A method for measuring the amount of ionizing radiation in a liquid substance. Samples are mixed with a mixture of solvent, surfactant and scintillators that can convert beta particles into light energy, which can be measured. 